\title{
Cartografias e movimentos: problemas metodológicos de leitura da cidade contemporânea à luz de The view from the road
}

\section{Cartography and motions: methodological issues of reading the contemporary city in the light of The view from the road} Cartografias y movimientos: problemas metodológicos a la luz de The view from the road

\section{Gabriel Teixeira Ramos}

Universidade Federal de Goiás, Cidade de Goiás, Goiás, Brasil, ramosgabriel@ufg.br

\section{Resumo}

Pelo menos desde 1960, cartografias produzidas pelo urbanismo no campo dos deslocamentos urbanos têm se limitado ao posicionamento geográfico do observador, desconsiderando, em boa medida, a experiência encarnada dos sujeitos para além do visual, bem como os atores e agentes político-estratégicos de formação do território. Em 1965, Kevin Lynch, Donald Appleyard e John Myer publicam "The view from the road" e estabelecem uma metodologia de análise da qualidade da forma visual da cidade contemporânea a partir de estradas. Inauguram, em certa medida, uma leitura através do para-brisa do automóvel em movimento, engendrando, assim, um estudo por eles alcunhado de "estética das estradas urbanas". Tal obra foca no posicionamento geográfico de dentro do automóvel e não considera em seu escopo quaisquer relações político-estratégicas acerca da aproximação desses sujeitos com aquele percurso ou espaço produzido. Nesse sentido, este artigo considera que é a partir da virada cartográfica e tecnológica ocorrida nos anos 1980 que a cidade contemporânea tem demandado uma complexidade cada vez maior na realização de leituras dos deslocamentos urbanos, que ocorrem enquanto disputa entre fluxos distintos experimentados e suas cartografias. De uma maneira incipiente, este problema aparece em "The view from the road", mas bastante vinculado ao que se vê na paisagem, desconsiderando a diversidade e qualidade dos fluxos das vias. Para esta comunicação, busca-se dar visibilidade às importantes considerações metodológicas elencadas pelos planejadores nesta obra, no que diz respeito à ampliação do repertório do urbanismo a partir da imagem em movimento, indicando a necessidade de atualização das mesmas e de 
inserção de uma camada política do ato de cartografar, em conexão ao que Fredric Jameson alcunhou como "nova estética do mapeamento cognitivo".

Palavras-chave: cartografia; movimentos; velocidade; deslocamentos; The view from the road.

\section{Abstract}

At least since 1960, cartography produced by urbanism in the field of urban displacement has been limited to the geographical position of the observer, largely disregarding the incarnate experience of subjects beyond the visual, as well as the actors and political-strategic agents of formation. of the territory. In 1965, Kevin Lynch, Donald Appleyard, and John Myer publish "The View from the Road" and establish a methodology for analyzing the quality of the contemporary city's visual form from roads. To some extent they open a reading through the windshield of the moving car, thus engendering a study they call the 'aesthetics of urban roads'. This work focuses on the geographical positioning of the car and does not consider in its scope any political-strategic relations about the approximation of these subjects with that path or space produced. In this sense, this communication proposal considers that it is from the cartographic and technological turn occurred in the 1980s that the contemporary city has demanded an increasing complexity in reading urban displacements, which occur as a dispute between distinct flows experienced and their cartographies. Incipiently, this problem appears in "The view from the road", but closely linked to what is seen in the landscape, disregarding the diversity and quality of road flows. For this communication, we seek to give visibility to the important methodological considerations listed by the planners in this work, regarding the expansion of the urbanism repertoire from the moving image, indicating the need to update them and insert a political layer. of cartography, in connection with what Fredric Jameson called the "new aesthetic of cognitive mapping."

Keywords: cartography; movements; speed; displacements; The view from the road. 


\section{INTRODUÇÃO}

\section{KEVIN LYNCH EM MEIO AO URBANISMO RODOVIARISTA}

Enquanto muitos países europeus, entre 1960 e 1980, sofriam os limites da urbanização, os EUA experimentavam um espraiamento territorial cada vez maior ${ }^{1}$, marcado, sobretudo, pela consolidação do ideário "American dream"2, propagado décadas antes. No contexto de 1960, este pensamento tomava seus contornos ainda mais robustos, com a forte profusão do imaginário da casa própria nos subúrbios e dos altos investimentos nas rodovias para automóveis privados.

Esse ideário estadunidense se impregnou no campo urbanístico, reverberando em toda uma geração de arquitetos e urbanistas. Modificava-se a compreensão de uma dada "totalidade" urbana, realocando-a para uma experiência de cidade, por parte dos planejadores, estritamente relacionada ao que se vê na paisagem. Mais especificamente, a partir de um ponto de visada privilegiado de dentro do automóvel, numa espécie de "virada rodoviarista" nas metodologias de estudo e análise do campo do urbanismo ${ }^{3}$.

A apreensão urbana a partir do automóvel se tornaria hegemônica e se consolidaria como importante eixo estruturante do imaginário estadunidense, por meio de transformações na apreensão, representação e construção de cidades e edifícios. Molda-se, assim, um campo próprio, observado por meio da cultura produzida pela arquitetura dos estacionamentos, seja da passagem pelos drive-thru à permanência pelos drive-in, que englobam, até os dias atuais, relações com fins de alimentação, entretenimento e de relacionamentos ${ }^{4}$.

1 Segundo o estudo de Lopez (2014), a população total dos EUA em áreas metropolitanas, entre as décadas de 1970 e 1980, tem um aumento de quase 10\% da suburbana (de 37\% para 46\%). Já na década de 2010, esta ultrapassa a urbana, com mais de $50 \%$ da população morando em subúrbios. Cf.: LOPEZ, R. Urban Sprawl in the United States: 1970-2010. Urban Long-Term Research Area Exploratory Awards (ULTRA-Ex). In: Cities and the Environment (CATE), Vol. 7 [2014], Iss. 1, Art. 7. Disponível em:<https://digitalcommons.Imu.edu/cgi/viewcontent.cgi?referer=https://www.google.com/\&httpsredir=1\&article=1131\&context=cate> Acesso em 21/10/2019.

2 James T. Adams, historiador e autor de "The Epic of America" (1931) foi o responsável por criar o termo "American dream", que consiste na ideia liberal de prosperidade, sucesso e mobilidade para deslocamentos, circunscrevendo um pensamento que perpassa gerações: "[a dream] of being able to grow to fullest development as man and woman, unhampered by the barriers which had slowly been erected in older civilizations" (ADAMS, 1931, p.405 apud RANK, 2014, p.2).

3 Se a ideia de "totalidade" foi contemplada, durante boa parte da história da cartografia e geografia a partir de objetos-mapas, observamos isso se aguçar ainda mais a partir do surgimento das primeiras aeronaves para voos comerciais, no início do século XX, e sua posterior utilização para fins bélicos, na Primeira Guerra Mundial (19141918). Apostamos que, com a "virada rodoviarista" dos anos 1960, há impactos consideráveis que acoplam as duas formas de leitura (visão de topo e a visão em paisagem, a partir do carro).

$4 \quad$ Somado a isso, as manifestações artísticas que aparecem nesse momento deixam mais à vista a incorporação da velocidade à apreensão urbana, tal qual no trabalho do artista da pop art, Ed Ruscha. Suas obras deste período são pautadas por uma estética rodoviarista, a partir do acoplamento de uma forma específica de se observar e fotografar, que pode ser notado de maneira bastante contundente no livro-obra "Every building on Sunset Strip", de 1966. Em um importante ensaio fotográfico em que instalara uma câmera no alto de um carro, Ruscha captou os edifícios da Sunset Strip, em Los Angeles, espacializando visualmente os dois lados da via em um livro sanfonado, que, ao ser aberto por completo, desenvolve-se por sete metros de comprimento, concebendo uma outra experiência desse local. 
As formas de representação urbana a partir da visada do automóvel tomam novos contornos no campo da arquitetura e urbanismo, em especial, com estudos empreendidos por pesquisadores da paisagem e morfologia urbana ${ }^{5}$. Uma das referências do campo na leitura e desenho da cidade é Kevin Lynch, que produz algumas de suas célebres obras, como "The image of the city", em 1960 e "Site planning", em 1962, (esta, junto com Gary Hack). "The image of the city" (1960) se consolidou como uma das mais importantes obras do campo do urbanismo, sendo incorporada em estudos de leitura e compreensão da paisagem, e considerada por muitos pares como basilar nas análises urbanas em cidades ocidentais. Destaca-se por ser um estudo que realiza ampla visão de reconhecimento de áreas urbanas, a partir de percepções do próprio autor, mas também por meio de uma pequena amostra dos moradores das três cidades estadunidenses estudadas: Boston, Jersey City e Los Angeles. Seu desdobramento ocorre em análises de como sujeitos organizam visualmente suas cidades, sobretudo, daquilo que consideram especificidades nas imagens delas criadas. Isso ocorre através da relação de construção de uma identificação visual, a partir da passagem de tempo: "Como obra arquitetônica, a cidade é uma construção no espaço, mas uma construção de grande escala; uma coisa só percebida no decorrer de longos períodos de tempo." (LYNCH, 1997, p.1).

Em sua trajetória de professor e pesquisador do MIT, Lynch se notabilizou por tal obra, por meio do estudo de uma qualidade visual presente nas cidades. Para isso, estabeleceu um glossário de noções visuais a fim de compreender a incidência desta identificação com o visual urbano (legibilidade, construção da imagem, estrutura e identidade e imaginabilidade). É uma significativa característica de sua metodologia a distância epistemológica do sujeito observador (usuário/morador) com o objeto observado (cidade), fato que, em boa medida, indicam uma ética e estética rodoviarista. Suas análises se apoiam, sobretudo, em percepções, sensações e emoções, relacionadas aos espaços (segurança, prazer, identificação etc.), sendo utilizados para isso elementos visuais presentes na cidade que o auxiliariam nesta abordagem (vias, marcos, limites, pontos nodais e bairros) advindas de um olhar externo aos acontecimentos (llustração 1$)^{6}$.

$5 \quad$ Na circunscrição deste campo específico da velocidade e dos deslocamentos urbanos, além desta obra, é inconteste a importância de "Learning from Las Vegas: the (forgotten) symbolism of architectural form" (VENTURI; SCOTT BROWN; IZENOUR, 1972), a qual não abordamos neste texto por limitações de espaço, mas que é importante de ser considerada. Esta obra é publicada sete anos à frente de "The view from the road" (1965), e dessa vez, é produzida por professores ligados à Universidade de Yale: o casal Robert Venturi e Denise Scott Brown, em parceria com Steven Izenour. Através dele, apresentam-se métodos e esquemas específicos para analisar a comunicação urbana a partir da velocidade, desafiando, sobretudo, a representação urbana vigente. Analisa-se a paisagem do corredor comercial pelo ponto de vista do motorista, visando-se estabelecer uma interpretação da arquitetura do corredor (Strip) comercial de Las Vegas, do simbolismo na arquitetura e da iconografia do espraiamento urbano (urban sprawl), consolidando-se como grande marco teórico do pós-modernismo na arquitetura (JAMESON, 1996).

$6 \quad$ Consideramos a estruturação de pensamento de Kevin Lynch e seus congêneres inspirada, principalmente, em algumas teorias fenomenológicas, sobretudo a de Maurice Merleau-Ponty (1999), com a fenomenologia da percepção. Por ela, podemos afirmar que haveria a necessidade de voltarmos a compreender os fenômenos para a análise da percepção, fazendo-nos mão do corpo próprio, estabelecendo o que o autor chama de "experiência perceptiva”, com sua percepção real e a lógica vivida. Além disso, muito deste movimento realizado por Lynch contribui para a teoria do lugar proposta pelo arquiteto norueguês Christian Norberg-Schulz (1980). Para ele, o urbanista estadunidense construirá em suas análises uma leitura da qualidade ambiental como um dos fatores principais a 


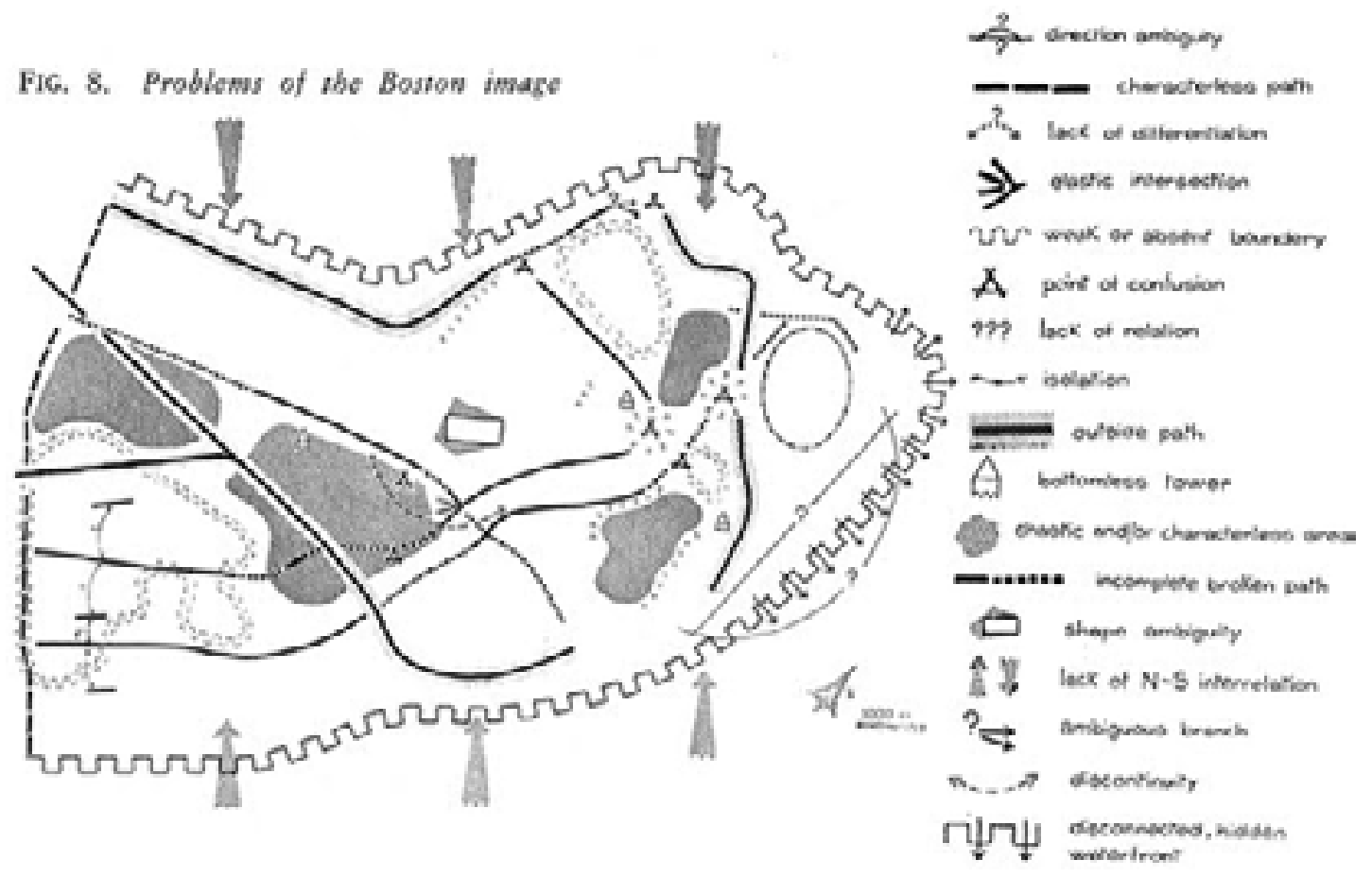

Ilustração 1 - Problemas na imagem de Boston. Autor: Kevin Lynch. In: LYNCH, K. The image of the city. Cambridge: MIT Press, 1960.

Fonte: Acervo próprio.

Indubitavelmente, podemos afirmar que a obra de Lynch marca uma geração de arquitetos e urbanistas, planejadores, geógrafos e outros profissionais ou leigos que em muito se interessam pela leitura da cidade. Talvez o caráter de um certo engajamento subjetivo angariado tão fortemente nas sensações permita uma gama de interseções de áreas, além de investimentos propositivos por parte de distintos atores, construindo um importante movimento de expansão do campo disciplinar do urbanismo. No entanto, um ponto ainda muito pouco explorado pela academia, e que a nós muito interessa, incide sobre a forma de pensamento na qual Kevin Lynch estava inserido ao publicar, individualmente ou em coautoria, um conjunto de obras que trata da forma visual urbana, em seu mais profícuo período de atuação, entre 1960 e 1980.

Naquele momento, Kevin Lynch era cidadão estadunidense, professor e pesquisador do MIT. Mesmo não influenciado diretamente e sendo de outra geração, há de se convir que estava imerso à efervescência cultural advinda das décadas de consolidação do American Dream. Além disso, observava o fortalecimento da "geração beat", fortemente marcada pela ideia de liberdade e fuga com seus carros. Presenciava ainda o momento da decadência do projeto da cidade moderna e a embrionária ascensão de experiências da pós-modernidade no contexto mundial (JAMESON, 1991). É nesse proteger o homem de estar perdido, à medida que se identifica e se relaciona com seu contexto. 
bojo em que ensaiamos a hipótese de que o automóvel não somente seria um importante pano de fundo para seus estudos, como seria mais do que isso: um eixo estruturante que condicionaria seu pensamento urbano e o de seus congêneres. Este fator pode ser percebido em boa parte de suas justificativas visuais das cidades, especialmente, no que diz respeito à distância física que toma para suas análises urbanas de conjunto. Tal argumentação presente nessa comunicação se confirma especialmente plantada em "The view from the road" (APPLEYARD; LYNCH; MYER, 1965), trabalho inicial dos urbanistas em compreender problemas da forma visual das cidades tendo como meio de análise a estrada, partindo de noções de totalidade e movimento.

\section{THE VIEW FROM THE ROAD}

\section{UMA ESTÉTICA DAS ESTRADAS URBANAS}

"The view from the road" (APPLEYARD; LYNCH; MYER, 1965) é um dos trabalhos menos conhecidos de Kevin Lynch, em parceria com outros dois professores do MIT, Donald Appleyard e John Myer. Trata-se de uma monografia publicada em 1965, sendo um dos primeiros estudos urbanos contemporâneos a partir da velocidade. Em boa medida, é um trabalho em que apostamos condicionar o pensamento presente nas obras de Kevin Lynch, tendo em vista ser a estrutura desse livro um dos primeiros interesses metodológicos do autor?

Nesta publicação, os autores inauguram uma leitura urbana através do para-brisa do automóvel em movimento, mas também observada em rebatimentos metodológicos concebidos no urbanismo, presentes e absolutamente difundidos até os dias atuais, mesmo que seja lateralmente, em termos de conteúdo, mas incisivamente em no que diz respeito às análises. Ao circularem pelas cidades de Nova lorque, Hartford, Boston e Filadélfia, engendram um campo por eles alcunhado de "estética das estradas urbanas", no intuito de compreender como as "estradas olham para os motoristas e seus passageiros e o que isso implica em seu desenho" (APPLEYARD; LYNCH; MYER, 1965, p.21, tradução nossa). Tal interpretação considera a qualidade da forma visual das cidades estadunidenses deficitária, sendo necessário reestabelecer coerên-

$7 \quad$ Plantamos tal informação a partir de uma informação ainda pouco difundida. Em 1958, antes, portanto, da publicação de "The image of the city" (1960), Lynch realiza um primeiro estudo a partir da estrada, utilizando a imagem em movimento como ferramenta, produzindo o time-lapse "Full Day" em Boston, disponibilizado no site do MIT. Cf.:LYNCH, K. The view from the road. From the Vault, MIT. Full Day, 1958 BCP '47. "Professor Kevin Lynch BCP '47 produced this time-lapse film showing 24 hours as viewed from the Memorial Drive side of the MIT campus, looking across the Charles River towards the city of Boston, as part of his studies into the theory of city form and human perceptions of the city. MIT Museum Collections". Disponível em: <https://mit150.mit.edu/multimedia/vault.html> Acesso em 22/10/2019. 
cia e ordem na escala metropolitana. A proposta é, portanto, criar uma metodologia de análise e desenho a partir de estradas (highways), já que, para os autores, elas possuiriam uma característica importante para o desenho urbano: sequências visuais dadas a um observador em movimento, o que poderia significar maior compreensão da coesão na paisagem.

A publicação é dividida em cinco tópicos, respectivamente: "The Highway Landscape"; "Recording Highway Sequences"; "Analysis of an Existing Highway"; "Methods of Design"; e "In Conclusion". Por conta do caráter monográfico, tais tópicos podem ser compreendidos de maneira objetiva em três partes: introdução e montagem da discussão em "The Highway Landscape"; problematização das metodologias existentes àquele contexto e necessidade dos autores em atualizá-las, respectivamente, apresentadas nos tópicos "Recording Highway Sequences" e "Analysis of an Existing Highway; e, por fim, um estudo de caso em Boston, em "Methods of Design", em que os autores experimentam sua metodologia.

No início da monografia, os autores argumentam a necessidade da realização da pesquisa a partir da produção de uma "estética das estradas urbanas", que seria a forma como as estradas "olhariam" para motorista e passageiros, implicando em um tipo de desenho específico (APPLEYARD; LYNCH; MYER, 1965, p.2). Nesse sentido, para eles, ao observar as estradas, o motorista deve ter prazer, ou, minimamente, sentir estar num trabalho de arte, devendo haver por isso clareza na leitura urbana por parte do observador. Por serem grandes sequências visuais, as estradas permitiriam uma compreensão em conjunto, podendo o motorista decifrar sua organização em termos de forma, sobretudo, com auxílio de símbolos de uso e da relação dele com elas.

Para estabelecerem essa acepção da experiência da rodovia em meio à sua materialidade, os urbanistas fazem mão de percepções próprias e de entrevistados. Direta ou indiretamente, na proposta de interpretação dos autores, os usuários acabam por elaborar informações a partir de aspectos visuais: sensação de dirigir como uma implicação entre movimento e espaço que só pode ser percebida por meio de uma sequência visual contínua; visão como principal sentido, enquanto o toque teria uma contribuição secundária, a partir de respostas do carro a mãos e pés; percepção de sequência espacial como uma arquitetura em larga escala; continuidade de fluxo temporal comparada à música e ao cinema; e sensações sinestésicas enquanto uma espécie de dança ou parque de diversões (Ibid.).

Ao estabelecerem o início de suas análises, os pesquisadores vão colocar como exemplo uma primeira sequência visual, que mostra, paradoxalmente, um percurso de um pedestre em um santuário japonês (Goshojinja, Kamakura, Ilustração 2). Segundo os autores, a comparação se justifica para mostrar um exemplo plausível de "sucessão rítmica, revelação progressiva, continuidade, recordação" (Ibid, p.4)

$8 \quad \mathrm{Tal}$ análise remete bastante aos esquemas de visão seriada de Gordon Cullen, propostos em "Towns- 


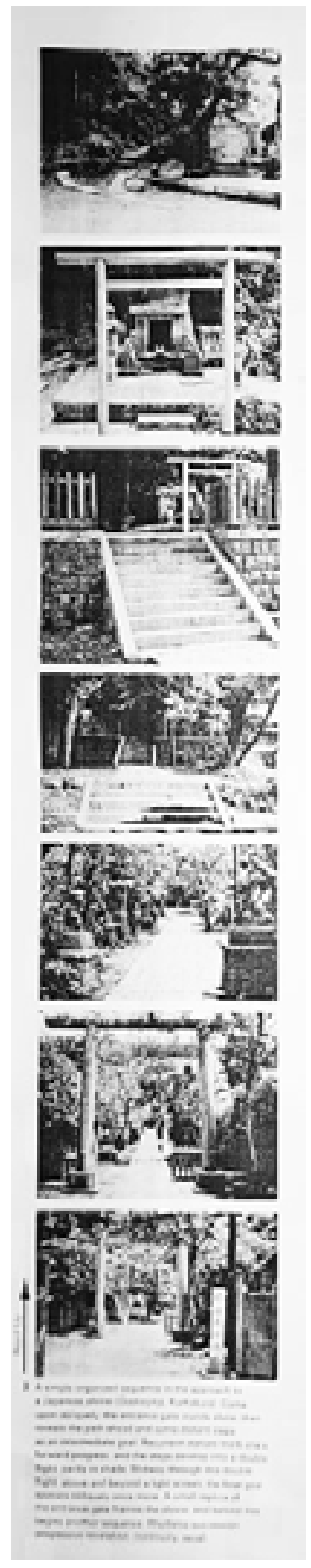

llustração 2 - Sequência visual de baixo para cima de um percurso de um pedestre em um santuário japonês situado em Goshojinja, Kamakura. Autores: Donald Appleyard, Kevin Lynch e John Myer. In: APPLEYARD, D.; LYNCH, K.; MYER, J. The view from the road. Cambridge: MIT Press, 1965, p.3. Fonte: Acervo próprio.

cape" (1961:1996), obra publicada como "The Concise Townscape", em 1971, única edição que foi traduzida para o português, em 1983, como "A paisagem urbana" reduzida, por fim, aos dois primeiros capítulos: "Definições" e "Aplicações", adquirindo explicitamente um caráter de manual. A partir dessa obra, desenvolve aquele que se torna um dos estudos mais difundidos nas faculdades de arquitetura e urbanismo, com a inovação do autor em incorporar no seu "diagnóstico urbano" a visão dos sujeitos de maneira espontânea. Desenvolve a noção de paisagem urbana em estratégias de compreensão visual da harmonia de edifícios e espaços urbanos, abarcando caráteres subjetivos e semióticos, como, por exemplo, monotonia e surpresa, numa proposta de representação urbana a incorporar a velocidade do pedestre. 
É importante de se considerar que esse esquema fotográfico é a primeira de inúmeras imagens a aparecerem do tipo "read up", em que propõem ler a via, de baixo para cima, quadro a quadro (frame to frame), o que também acaba por condicionar o tamanho de toda a monografia para um formato A3 retrato. Essa forma de leitura intriga por um problema específico, que é a visualidade de uma paisagem em uma fita de formato retrato. Além das fotografias, ao longo da publicação, podem ser observadas esquemas de croqui curvilíneos que fazem alusão à dinâmica do movimento nas vias, compostas por setas (llustração 3).
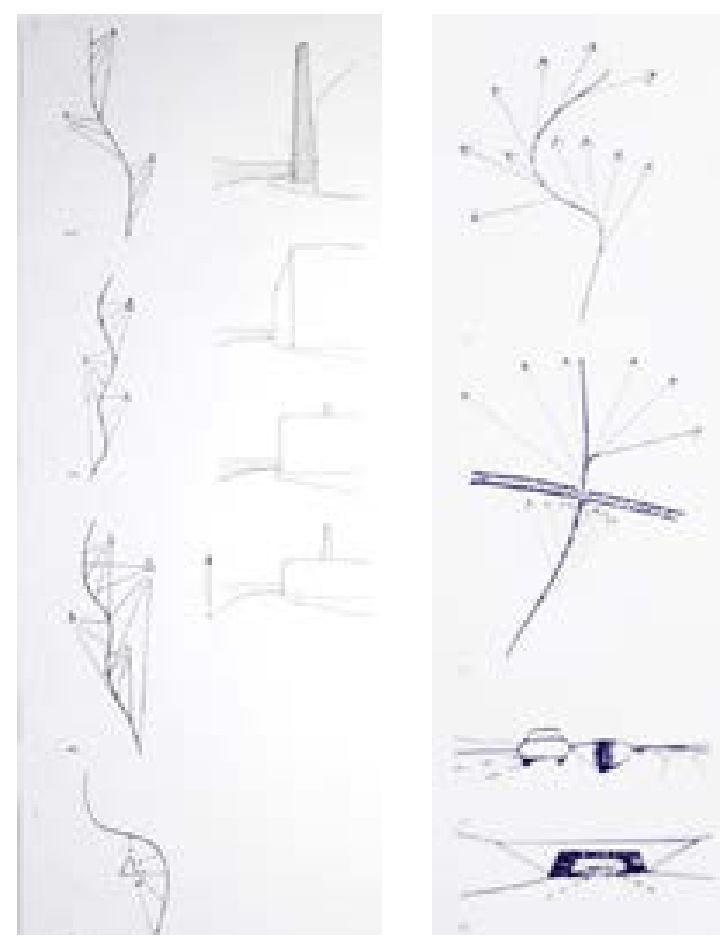

Ilustração 3 - Esquema visual de baixo para cima de um trecho da rodovia. Autores: Donald Appleyard, Kevin Lynch e John Myer.

Fonte: APPLEYARD, D.; LYNCH, K.; MYER, J. The view from the road. Cambridge: MIT Press, 1965, p.3.

No decorrer do trabalho, os autores vão considerar que o desenho ao qual é submetida a estrada tem como principais objetivos "[fazê-la] derreter na paisagem, outdoors devem ser controlados, as cicatrizes da construção devem ser disfarçadas pelo plantio" (Idem). Destacam, assim, a importância de se compreender essa paisagem pelo olhar de motoristas e passageiros, esquivando-se deliberadamente de questões externas à experiência automotiva e à estrada, propriamente dita. Para essa explanação, determinam quatro tipos de sujeitos para analisar distintas formas de apreensão dessa experiência urbana visual: o turista, com o frescor da novidade na visão e a possibilidade de engendrá-la continuamente num processo de estranhamento e reorientação do território; o viajante habitual, desinteressado pela visão da paisagem, pois tem somente o intuito de se deslocar; o motorista, com a visão frequente das cenas, limitada a uma angulação frontal e concentrada nos próprios acontecimentos da estrada; e o passageiro, livre para ter ou não a visão ao seu redor, despreocupada com o tráfego imediato.

Uma hipótese dos autores incide sobre motorista e passageiro serem "provavelmente um público desatento, mas cativo, que não podem evitar a observação, ainda que subconscientemente, dos eventos mais dramáticos de uma cena que é móvel e perigosa demais para ser ignorada" (lbid.). Assim, outras percepções sensoriais acabam por ser diluídas, pois "somente a velocidade, a escala e a graça de seu movimento podem compensar essas limitações" (Ibid., p.22). Sinteticamente, nesse trabalho, os 
autores iniciam uma discussão que contempla a paisagem visual e o desenho urbano ao qual são submetidas as estradas, sob o ponto de vista de quem está em alta velocidade, protegido de intempéries pelo anteparo do para-brisa.

Estabelecem quatro tipos de usuários: viajante habitual, motorista, turista e passageiro, destacando a necessidade de comparar esses sujeitos (de dentro do carro) ao pedestre que está do lado de fora, seja pelos aspectos negativos - principalmente, o fato de estarem sujeitos às intempéries - e positivos - no que diz respeito à velocidade, escala e "graça" desse movimento que condicionam características dessa especial experiência. É sob este ponto que a publicação analisa, à distância, os elementos que deteriam a atenção de motorista e passageiros, como a presença ou ausência de objetos na pista ou a ela adjacentes; a velocidade que condicionaria o ângulo de visibilidade do condutor; e a qualidade da iluminação. Visa-se perceber também a qualidade da sensação de movimento, que também incidiriam sobre a presença ou não de detalhes à beira da estrada; a aparente rotação de objetos próximos relacionados a outros distantes; a irradiação da iluminação externa sobre texturas; a ilusão visual de crescimento ou diminuição dos objetos; dentre outros. Observa-se ainda o que os autores chamam "extensão de si mesmo" (extension of self) que, a partir de um acoplamento e automatização do ato de dirigir, condicionaria o motorista a se estabilizar ou neutralizar aquela sensação até alguma mudança de nível específica, em uma "sensação de maestria" (sense of mastery).

Nos aspectos metodológicos, concentrados mormente na segunda parte da obra, os autores consideram o problema da leitura em movimento, objetivando pensar a via como o cinema:

Se nós quisermos modificar a visão através da rodovia, a primeira coisa a se fazer é desenvolvermos uma técnica de gravar, analisar e comunicar suas sequências visuais. Sem essa técnica, nós somos incapazes de expressar ou refinar as alternativas de desenho, faltando construir e reconstruir estradas em grande escala. Isso seria análogo à música sem nota, ou arquitetura sem desenhos. Ambas são possíveis (e já ocorreram), mas o crescimento da arte é, assim, limitado (Ibid., p.19, trad. nossa).

Para os autores, um mapa detalhado pode mostrar locais e níveis de uma rodovia, associado à topografia, vegetação e acidentes geográficos. Entretanto, somente isso não daria conta de se compreender o movimento da pista, sendo necessário mais dados a partir de fotografias, croquis rápidos, ou pelo próprio cinema, que gravaria de maneira ainda mais específica o movimento. É a partir desse ponto que os autores vão estabelecer uma linguagem que busque "simular o escaneamento de um olho humano" (lbid., p.20, llustração 4), a partir da câmera, o que resultaria em um trabalho de arte, de modo que a "vista do pedestre - ou a partir de um automóvel, avião, ou qualquer outro veículo - ao longo de qualquer trajetória e velocidade seria facilmente simulado" 


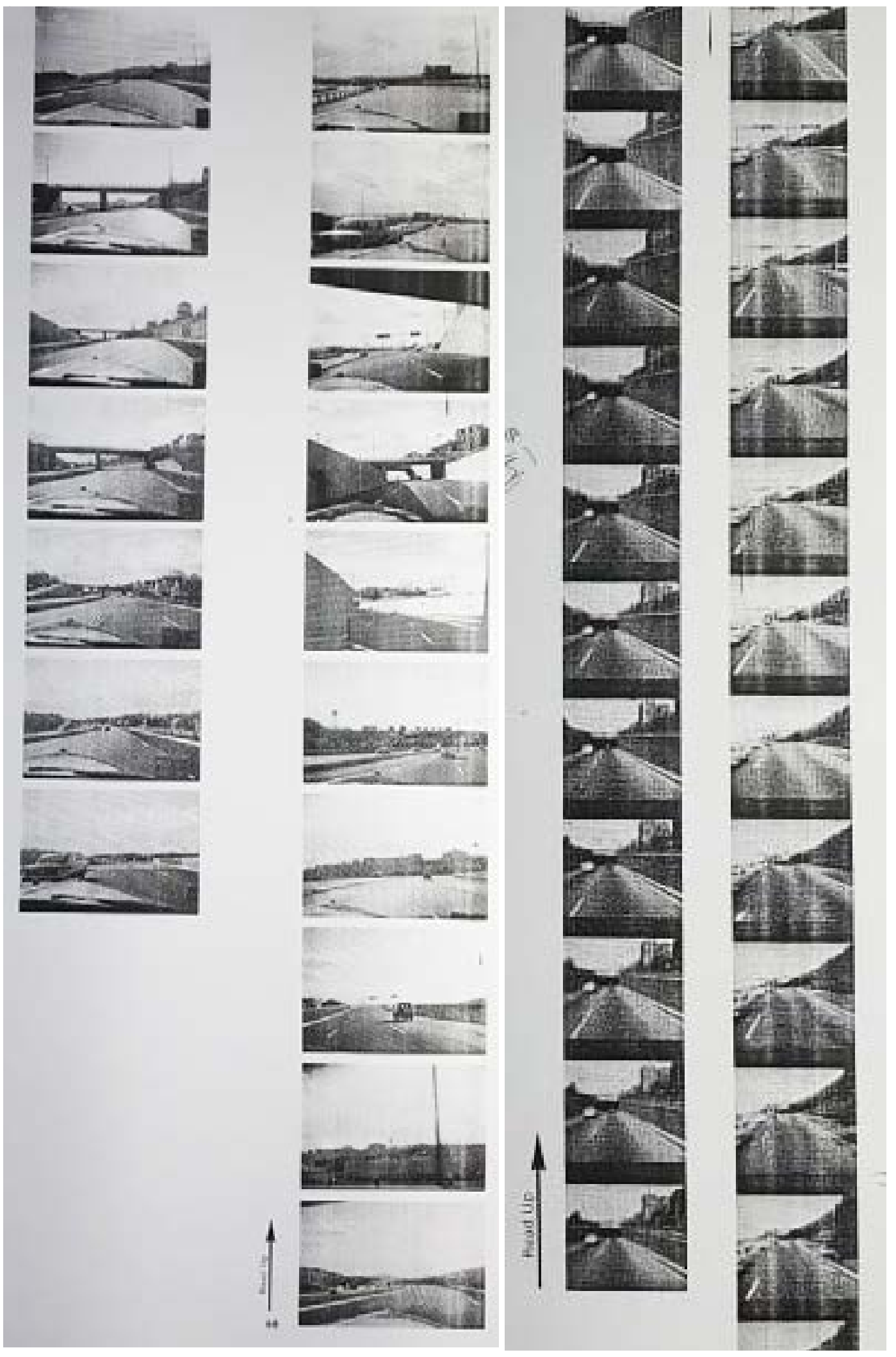

Ilustração 4 - Esquema visual de baixo para cima de um trecho da rodovia com fotografias de dentro do automóvel. Autores: Donald Appleyard, Kevin Lynch e John Myer.

Fonte: APPLEYARD, D.; LYNCH, K.; MYER, J. The view from the road. Cambridge: MIT Press, 1965, p.3. 
A partir dessa leitura, os planejadores, e também cineastas, elaboram estudos em vídeo, tendo uma câmera acoplada dentro de um automóvel e, dessa forma, estabelecem novas incursões de dentro do carro. Ao longo da obra, consideram que a experiência da rodovia consiste nos detalhes presentes nela, considerando como hipótese central uma interpretação da cidade por meio de uma sequência em movimento, pois somente assim é possível de compreender um conjunto. O movimento daria margem à interpretação por meio de mudanças (de luzes dos postes, sinais de comunicação, transição de trilhos, texturas da pavimentação etc.) e significados através de técnicas de comunicação (como a orientação local e a experiência do movimento em relação a si mesmo ou ao ambiente).

Para isso, consideram a necessidade de se estudar a "experiência do movimento" (experience of motion), dividindo esse método em três partes, na leitura da velocidade e da direção, sempre a partir do que se vê na paisagem: um aparente movimento próprio (apparent self motion) e suas mudanças (paradas e idas; acelerações e desacelerações; subidas e descidas; viradas à esquerda e à direita); um aparente movimento do campo de visão (apparent motion of the visual field) e suas mudanças (passagens ao lado, acima, em baixo; rotações; translações; espraiamentos e contrações dos contornos e texturas; estabilidades e instabilidades; velocidades aparentes ou falta delas); e as características espaciais: presença e posicionamento de objetos acoplados à via, sua consistência e nível de circunscrição dos mesmos; proporções gerais do espaço circunscrito, escala a partir do observador e sua posição; qualidade da luz, sua intensidade e direção; relações dos espaços em sequência, por justaposição ou sobreposição; além da direção das vias principais, que condicionam os olhares (lbid., p.21).

A partir dessas constatações e da necessidade de uma leitura em conjunto da cidade, considerando o movimento do automóvel, ao final da análise, os planejadores realizam um estudo projetual em Boston, propondo um novo anel viário para a região do Mystic River. A região em questão (Figura 5) se trata de um grande ameboide circular e excêntrico, que se sobressai da área central, alcançando as porções leste, sul e norte da cidade (no mapa, de cor cinza) e a proposta, por sua vez, aparece em um formato mais triangular (no mapa, de cor preto). 


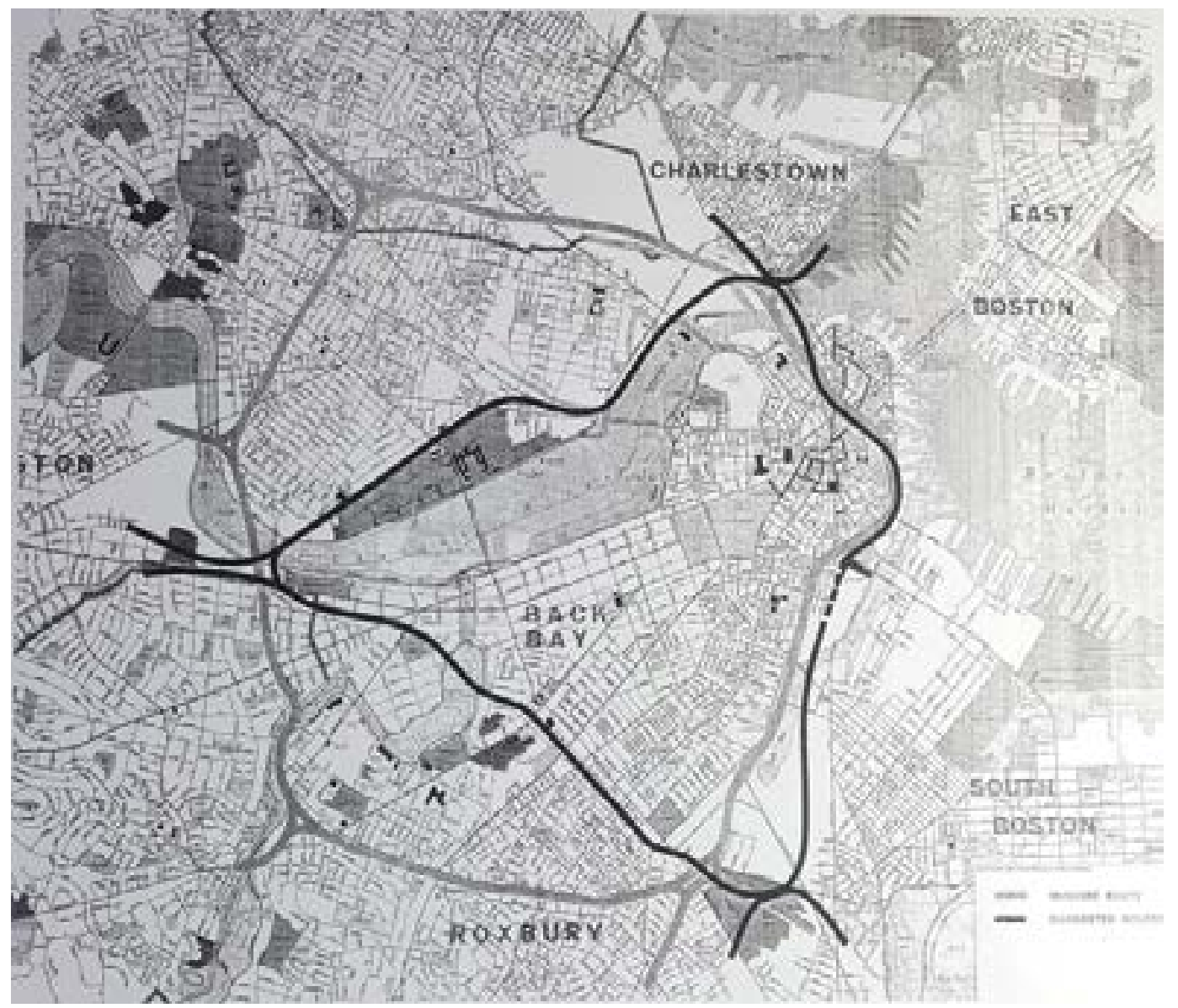

Ilustração 5 - Mapa esquemático com o anel viário de Boston estudado pelos planejadores e a estrutura lida por eles. De cinza, o anel original e de preto a proposta. Autores: Donald Appleyard, Kevin Lynch e John Myer. Fonte: APPLEYARD, D.; LYNCH, K.; MYER, J. The view from the road. Cambridge: MIT

Press, 1965, p.3.

Os autores propõem um novo anel, que seria menor, um ameboide triangular, mas mantendo a excentricidade. Esse anel visa melhorar a orientação do motorista bem como realizar conexões mais rápidas, intuitivas e estar mais vinculado ao centro da cidade, pois nesse local, a vista "é sempre excitante" (Ibid., p.40). Para isso, realizam uma série de comparações a partir dos estudos de qualidade da imagem, apresentados por Lynch em "The image of the city" (1960), citado na obra.

\section{CARTOGRAFIAS E DESLOCAMENTOS PARA ALÉM do QUE (NÃO) SE VÊ}

Como uma obra monográfica marcada por uma constatação de um problema 
(a coesão em se ler a cidade), seguida do desenvolvimento metodológico bastante original (utilizar da imagens em sequência) e a realização de um estudo de caso (projeto para o anel viário de Boston), os autores de "The view from the road" constatam itens importantes e atuais, em especial, no que diz respeito a um pensamento cartográfico que contempla várias camadas de visualização.

Em boa medida, é possível notar o esforço dos professores em investir em outras metodologias que entendam a complexidade do território urbano. Os instigantes diagramas pensados por eles inauguram um movimento bastante original que é pensar a cartografia para além da forma-mapa, investindo em fotografia, desenho e cinema. Ao compreenderem que o problema de se ler em conjunto uma cidade passa, substancialmente, pela incorporação do movimento, produzem uma dimensão bastante singular da leitura urbana.

A percepção dos urbanistas acerca desse tipo de metodologia, frame to frame, operacionaliza aquilo que Paul Virilio (1991) chamou de "movimento do movimento", próprio ao cinema, ou seja, as noções de aceleração e desaceleração presentes nele, bem como sua terminologia (montagem, corte, decupagem, roteiro etc.). Por vezes, os autores engendram no campo do urbanismo de maneira bastante consciente esses termos, como "road watching", "audience", "dramatic events of a scene"; em outras, pensam efetivamente a experiência da visão da estrada "como se fosse um filme ou uma gravação que deve ser curtida tanto quando avançada ou recuada" - "when played backward as well as forward" (APPLEYARD; LYNCH; MYER, 1965, p.5).

$\mathrm{Na}$ realidade, os autores engendram um campo específico próprio do campo urbanístico de maneira tão original que talvez seja esse um ponto a ser considerado para se pensar na influência de Lynch nas escolas de arquitetura e urbanismo de todo mundo. Entretanto, não há um trabalho programático que dê sequência a "The view...", embora apostemos ser ele um condicionante para a forma que guia o pensamento de Kevin Lynch em suas obras, como aparece em outras entre 1960 e 1980.

Em nossa pesquisa de doutorado em andamento ${ }^{9}$, tomamos dimensão desse campo, tentando constituí-lo a partir do urbanismo, mas atravessado pela arte e cinema. Mais especificamente, acreditamos que esse campo se constitua de uma leitura urbana sob o prisma dos deslocamentos e velocidades, tendo como filtro a imagem em sequência acoplada à cartografia, ou indo além, onde o pensamento cartográfico e o cinematográfico são fundidos. Observamos, ao longo da pesquisa isso aparecer em outros trabalhos como em Gordon Cullen, sua "Townscape" (1961) e as visões seriais; Robert Venturi e Denise Scott Brown, e sua leitura simbólica de Las Vegas, de dentro do automóvel, em "Learning from Las Vegas"; e Bernard Tschumi, com suas reflexões

9 "Entre velocidade e lentidão: cartografias do território urbano contemporâneo" (2017 - atual, PPG-IAU/ USP), sob orientação do Prof. Dr. David M. Sperling. 
sobre movimento em "The Manhattan Transcripts" (1980). Outros trabalhos aparecem lateralmente, mas essas obras nos direcionam a pensar representações da forma-mapa fundidas ao movimento.

O que nos chama atenção, mais explicitamente em "The view...", mas também nas citadas anteriormente, é a necessidade de pensarmos a leitura urbana dos deslocamentos além do que se vê na paisagem. Nesse sentido, consideramos nos reposicionarmos à leitura da velocidade contemporânea, pois apostamos que a mesma afeta os corpos de modo contundente, sendo importante compreender dimensões das mesmas. Constatamos que o urbanismo deva compreender disputas entre fluxos de velocidade e lentidão, aqui pensados a partir de Paul Virilio (1996) e Milton Santos (2001), como base para realizar representações urbanas que deem conta de investir em distintos aspectos estratégicos de formação do território urbano.

Para entender este problema, constatamos a necessidade de expansão da leitura para campos disciplinares e práticas que pensem uma "estética do mapeamento cognitivo" (JAMESON, 1996), engajando uma política no ato de cartografar (SPERLING, 2016). Observamos a importância de se pensar cartograficamente o contemporâneo a partir de técnicas de mapeamento que incorporem a dimensão coletiva e participativa. Além disso, entendemos a importância de ler aspectos que ainda não foram considerados nas tradicionais leituras urbanísticas da velocidade, como o caso de "The view...", que se tratam das estratégias de formação do território e das táticas de escape e contiguidade, que são postas em disputa a todo instante.

Em alguma medida, vemos como importante a realização de formas coletivas de fazer mapa que invistam esforços no processo político do ato de mapear. Além disso, observamos como fundamental as diversas leituras possíveis do cotidiano (CERTEAU, 2013), enquanto permeado por disputas, que também devem ser engendradas criticamente na visualização de novas camadas que compõem (e podem compor) o urbano. Principalmente, advindas das tecnologias da informação e das práticas hegemônicas de produção cartográficas, como GPS, SIG e as técnicas da Google (Maps, Street View, Earth etc.).

Com este breve panorama, e com a leitura da obra "The view from the road", espera-se que esta comunicação tenha conseguido abarcar o tema dos deslocamentos urbanos, sob a ótica da velocidade, e a leitura metodológica das formas de se lhes representar, compreendendo a complexa trama em que vivemos no presente, sendo fundamental que nos reposicionemos, metodologicamente, tanto por meio das formas mapas quanto das imagens em movimento. 


\section{REFERÊNCIAS}

APPLEYARD, D.; LYNCH, K.; MEYER, J. The view from the road. Cambridge: MIT Press, 1965.

CERTEAU, M. A invenção do cotidiano.: 1. Artes do fazer. Petrópolis: Vozes, 2013.

CULLEN, G. Paisagem urbana. São Paulo: Martins Fontes, 1983.

JAMESON, F. Pós-Modernismo: a lógica cultural do capitalismo tardio. São Paulo: Ática, 1996.

LYNCH, K. A imagem da cidade. São Paulo: Martins Fontes, 1997.

SANTOS, M. Elogio da lentidão. São Paulo: Folha de São Paulo, 11 de março de 2001.

SPERLING, D. Você (não) está aqui: convergências no campo ampliado das práticas cartográficas. In: Indisciplinar / EA-UFMG. Belo Horizonte (MG), V. Semestral, n.2, v.2 (2016), pp. 77-92.

TSCHUMI, B. The Manhattan Transcripts. London: Academy Editions, 1994.

VENTURI, R.; SCOTT BROWN, D.; IZENOUR, S. Aprendendo com Las Vegas: o simbolismo (esquecido) da forma arquitetônica. São Paulo: Cosac Naify, 2003.

VIRILIO, P. 1999. Espaço crítico. São Paulo: Editora 34.

. Velocidade e Política. São Paulo, Estação da Liberdade, 1996.

Artigo publicado originalmente nos Anais do $2^{\circ}$ SEPPAS - Seminário de Planejamento, Paisagem Urbana e Sustentabilidade, 4 a 6 de novembro de 2019/ Luana Miranda Esper Kallas (Org.). - Goiânia: Gráfica UFG, 2019.

Recebido em: 10/12/2019

Aprovado em: 16/10/2018

Publicado em: 19/12/2019 